\title{
BMJ Open Heavy smoking rate trends and related factors in Korean occupational groups: analysis of KNHANES 2007-2012 data
}

\author{
Bo-Guen Kim, ${ }^{1}$ Do-Dam Pang, ${ }^{1}$ Young-Jun Park, ${ }^{1}$ Jong-In Lee, ${ }^{2}$ \\ Hyoung-Ryoul Kim, ${ }^{2}$ Jun-Pyo Myong, ${ }^{2}$ Tae-Won Jang ${ }^{2}$
}

To cite: Kim B-G, Pang D-D, Park Y-J, et al. Heavy smoking rate trends and related factors in Korean occupational groups: analysis of KNHANES 2007-2012 data. BMJ Open 2015;5: e008229. doi:10.1136/ bmjopen-2015-008229

- Prepublication history for this paper is available online To view these files please visit the journal online (http://dx.doi.org/10.1136/ bmjopen-2015-008229).

Received 18 March 2015 Revised 2 September 2015 Accepted 21 October 2015

CrossMark

\begin{abstract}
${ }^{1}$ College of Medicine, The Catholic University of Korea, Seoul, Korea

${ }^{2}$ Department of Occupational and Environmental Medicine, College of Medicine, The Catholic University of Korea, Seoul, Korea
\end{abstract}

Correspondence to Dr Tae-Won Jang; om1024@hanmail.net

\section{ABSTRACT}

Objectives: The present study was designed to investigate the smoking and heavy smoking trends and identify possible related factors among Korean male workers from 2007 to 2012 by occupational groups.

Methods: The data were derived from the fourth (2007-2009) and fifth (2010-2012) waves of the Korean National Health and Nutrition Examination Survey (KNHANES). Occupational groups were categorised into three groups, which were non-manual, manual and service and sales groups. Age-adjusted prevalence rates of smoking and heavy smoking ( $>20$ cigarettes/day) in men aged 25-64 years were calculated. Factors associated with heavy smoking were investigated using logistic regression analyses.

Results: Smoking rate in manual workers decreased gradually over time ( $p$ for trend $<0.0001$ ). Smoking rate was higher in manual than non-manual workers, but the difference reduced over time ( $p$ for trend $<0.0001$ ). Heavy smoking rate decreased from 2007 to 2012 ( $p$ for trend $<0.0001$ ). Heavy smoking rate was higher in manual than non-manual workers; however, this difference increased over time. Stress, depressive mood and long working hours ( $\geq 60 \mathrm{~h} /$ week) were associated with heavy smoking.

Conclusions: Antismoking policy should focus on current and heavy smokers. Workplace antismoking programmes should consider working hours and stress, especially in manual workers.

\section{INTRODUCTION}

Smoking is one of the main risk factors for many diseases. Cigarette smoking can cause cancers of the lung, oral cavity, pharynx, larynx, oesophagus, pancreas, bladder and reproductive system, ${ }^{1}{ }^{2}$ chronic lung diseases, ${ }^{3}$ cardiovascular diseases ${ }^{4}$ and others. Smokers are reported to have their life expectancy shortened by at least one decade in the USA. ${ }^{5}$ Therefore, many countries have implemented policies to reduce smoking rates including restriction of tobacco advertising, limitations on the age at which cigarettes can be bought, and the creation of smoke-

\section{Strengths and limitations of this study}

- The data analysed in this study were derived from a well-designed systematic nationwide survey.

- This study identified the work-related factors associated with heavy smoking.

- Smoking status of 'current smoking' was not clearly defined, which would lead to an underestimation of the smoking prevalence rate.

- Socioeconomic status, education and other factors which might be related to heavy smoking were not considered.

free areas. In South Korea, comprehensive smoking control policies have been in place since 1995, and smoking prevalence among men has reduced. ${ }^{6}$

There are synergistic effects between smoking and hazardous substances in the workplace such as asbestos, ${ }^{7}$ chemicals, ${ }^{8}$ radon $^{9}$ and others. ${ }^{10}$ Workers who both smoke and are exposed to hazardous substances are at high risk of cancers of the lung and bladder. ${ }^{11}{ }^{12}$ Compared with nonmanual workers, manual workers are at increased risk of exposure to the aforementioned hazardous substances, with synergistic effects on health for those who also smoke. Therefore, a smoke-free working environment is important for a worker's health. ${ }^{13}$ Many companies recognised the importance of eliminating smoking in the workplace, and adapted policies to limit or prohibit smoking in their employees. ${ }^{14} 15$ Workplace antismoking programmes were reported to be effective in reducing the smoking prevalence in the general population, because people spend a lot of time in their workplaces. ${ }^{16}$ In South Korea, the smoking prevalence was higher in manual than in non-manual workers in 2009, suggesting that more active smoking control policies specific to manual workers were needed. ${ }^{17}$ 
The amount of smoking is also an important consideration because heavy smokers may be at greater risk than light smokers of smoking-related diseases. It was reported that there are dose-response relationships between smoking index (pack-years) and lung cancer, and between heavy smoking (current smokers with 20 or more packyears) and the risk of metabolic syndrome. ${ }^{18} 19$

Nevertheless, few studies about recent smoking trends among occupational groups focus on heavy smokers. Given the high risk of smoking-related diseases in manual workers, up-to-date research on smoking rate trends looking at heavy smoking and occupational groups is needed. The results will help to identify those groups that are at increased risk of smoking-related diseases and create helpful and appropriate interventions. This study was designed to investigate recent trends in the smoking rate and amount of smoking and identify possible related factors among Korean male workers of different occupational groups.

\section{METHODS}

\section{The data for analysis}

In South Korea, the Ministry of Health and Welfare and the Center for Disease Control jointly carry out the Korea National Health and Nutrition Examination Survey (KNHANES) periodically to evaluate Korean health and nutritional status. ${ }^{20}$ The first, second and third wave surveys were conducted in 1998, 2001 and 2005 , respectively. Since 2007, the survey has been conducted annually and data from 2007 to 2009 and from 2010 to 2012 were integrated, respectively, into the fourth and fifth wave surveys. Participants were selected for KNHANES from among non-institutionalised civilians using a stratified, multistage, clustered probability sampling design. This sampling method is certified as producing representative statistics by the Korean Department of Statistics. All KNHANES data are accessible from the KNHANES website (https:// knhanes.cdc.go.kr).

We analysed data obtained from the fourth (20072009) and fifth (2010-2012) wave surveys of KNHANES. In the fourth (2007-2009) KNHANES wave survey, 200 sampling units comprising 4600 households were randomly sampled every year. In the fifth (2010-2012) KNHANES wave survey, 192 sampling units comprising 3800 households were randomly sampled every year. In total, 1176 sampling units comprising 25200 households sampled from 2007 to 2012 were used in this study. Participants included men aged 25-64 years, whereas women, men aged $<25$ or $\geq 65$ years, the unemployed and students were excluded.

\section{Definitions of current smoking and heavy smoking}

Smoking status was assessed according to participants' answers to the question 'Do you currently smoke?' Participants were considered to be current smokers if they answered 'I smoke everyday' or 'I sometimes smoke', and reported that they had smoked more than five packs (100 cigarettes) in their whole life. A current smoker with a daily consumption of more than 20 cigarettes was considered to be a heavy smoker.

\section{Occupational groups}

In the fourth and fifth wave surveys, KNHANES categorised occupations into 11 groups. We classified these occupations into three groups: non-manual, manual and service or sales. Non-manual workers included general managers, professionals and office workers. Manual workers included those in the agriculture and fishing industries, crafts and related people, plant and machine operators, assemblers and those in elementary occupations (construction and mining).

\section{Variables associated with heavy smoking}

Work hours were classified into two groups: $\leq 60$ and $>60 \mathrm{~h}$ per week. Participants reported their level of stress as none, mild, moderate or severe. When a participant checked 'moderate' or 'severe', this participant was classified as being in the stress group. Depression was assessed by answers (yes or no) to the question "Have you experienced a depressed mood for two or more continuous weeks during the previous 1 year?" The answer 'yes' was taken to indicate that the participant had psychological stress. Suicidal thoughts were assessed by responses (yes or no) to the question "Have you thought about suicide during the previous 1 year?" Participants were asked whether they had been educated about smoking cessation during the previous year.

\section{Statistical analysis}

The age-standardised prevalence rates of current smoking and heavy smoking, stress, depression, suicidal thoughts, working hours and education about smoking cessation were calculated from data for each wave of KNHANES. Direct standardisation to 10 year age groups was performed using the age distribution of the 2005 and 2010 South Korean census populations as the standard population. Logistic regression analyses were performed to analyse the relationship between current or heavy smoking rate and occupational group in terms of the prevalence ratio (PR). Trends in the OR and PR were estimated by examining the $p$ value for an interaction term of occupations and the variables that identified the year of the data in the model. SAS for Windows V.9.2 (SAS Institute, Inc., Cary, NC, USA) was used for statistical analyses.

\section{RESULTS}

The age-standardised smoking rates in South Korean male current smokers (aged 25-64 years) are shown (table 1). The current smoking rate in manual workers decreased gradually over time ( $p$ for trend $<0.0001$ ). In contrast, the current smoking rate in non-manual and service or sales workers increased from 2007 to 2010/ 2011, after which it decreased ( $\mathrm{p}$ for trend $<0.0001$ ). 
Table 1 Age-standardised prevalence rates $(95 \% \mathrm{Cl})$, OR and prevalence ratio (PR) of current smokers; data on Korean men aged 25-64 years participating in the Korean National Health and Nutrition Examination Survey

\begin{tabular}{|c|c|c|c|c|c|c|c|}
\hline & 2007 & 2008 & 2009 & 2010 & 2011 & 2012 & $\begin{array}{l}p \text { For } \\
\text { trend }\end{array}$ \\
\hline Total & 47.8 (44.3 to 51.4$)$ & 50.6 (49.1 to 52.0$)$ & 49.9 (48.6 to 51.2$)$ & $52.0(50.2$ to 53.8$)$ & 50.1 (48.0 to 52.2) & 47.0 (44.9 to 49.0$)$ & $<0.0001$ \\
\hline Non-manual & 38.7 (30.1 to 47.2$)$ & 43.7 (39.2 to 48.2$)$ & 44.4 (40.1 to 48.7$)$ & 46.6 (41.7 to 51.5$)$ & 43.8 (38.6 to 48.9$)$ & 40.9 (35.3 to -46.4$)$ & $<0.0001$ \\
\hline $\begin{array}{l}\text { General managers and } \\
\text { professionals }\end{array}$ & $38.9(24.2$ to 53.5$)$ & 45.2 (38.1 to 52.3$)$ & 45.5 (38.3 to 52.6$)$ & 46.1 (37.5 to 54.6$)$ & 43.2 (34.8 to 51.6$)$ & 41.1 (31.4 to 50.8$)$ & - \\
\hline Office workers & 36.5 (15.1 to 57.8$)$ & 42.0 (26.9 to 57.2$)$ & 39.9 (32.5 to 47.4 ) & 46.1 (36.3 to 55.9$)$ & 45.2 (32.2 to 58.2 ) & 40.0 (27.4 to 52.7$)$ & - \\
\hline Manual & 57.0 (48.9 to 65.0$)$ & 56.1 (52.4 to 59.8$)$ & 55.6 (51.8 to 59.4$)$ & 57.8 (51.5 to 64.0$)$ & 54.5 (48.8 to 60.2$)$ & 50.6 (43.9 to 57.4$)$ & $<0.0001$ \\
\hline $\begin{array}{l}\text { Agricultural and fishery } \\
\text { workers }\end{array}$ & 52.5 (40.7 to 64.3$)$ & 63.4 (46.0 to 80.8$)$ & 47.1 (18.7 to 75.5$)$ & 43.7 (19.1 to 68.3$)$ & $43.9(0.0$ to 140.7$)$ & 55.4 (5.0 to 105.8$)$ & - \\
\hline $\begin{array}{l}\text { Craft and related workers, } \\
\text { plant and machine operators } \\
\text { and assemblers }\end{array}$ & 54.7 (43.0 to 66.4 ) & 56.3 (51.0 to 61.6$)$ & 56.0 (50.4 to 61.5$)$ & 56.5 (48.3 to 64.7 ) & 53.6 (45.1 to 62.1$)$ & 52.5 (42.6 to 62.4$)$ & - \\
\hline $\begin{array}{l}\text { Elementary occupations } \\
\text { (construction and mining) }\end{array}$ & $68.0(31.6$ to 104.4$)$ & 51.4 (26.8 to 75.9$)$ & 56.7 (37.7 to 75.8$)$ & 60.8 (24.6 to 96.0$)$ & 57.1 (32.2 to 82.0$)$ & 41.6 (3.81 to 79.4$)$ & \\
\hline Service or sales workers & 52.0 (36.4 to 67.5$)$ & 50.0 (40.8 to 59.3$)$ & 52.9 (43.9 to 62.0$)$ & 53.4 (43.0 to 63.9$)$ & 54.7 (43.8 to 65.5$)$ & 46.5 (29.6 to 63.4$)$ & $<0.0001$ \\
\hline OR of manual vs non-manual & 2.00 (1.43 to 2.80$)$ & 1.67 (1.33 to 2.10$)$ & 1.63 (1.32 to 2.01$)$ & 1.60 (1.20 to 2.13$)$ & 1.47 (1.11 to 1.94$)$ & 1.41 (1.05 to 1.88$)$ & $<0.0001$ \\
\hline OR of service vs non-manual & 1.96 (1.22 to 3.16$)$ & $1.31(0.94$ to 1.81$)$ & 1.46 (1.07 to 1.99$)$ & $1.32(0.97$ to 1.82$)$ & 1.56 (1.14 to 2.13$)$ & $1.13(0.73$ to 1.74$)$ & 0.0389 \\
\hline PR of manual vs non-manual & 1.33 (1.12 to 1.59$)$ & $1.14(1.02$ to 1.26$)$ & 1.10 (0.99 to 1.22$)$ & $1.10(0.99$ to 1.23$)$ & $1.08(0.96$ to 1.21$)$ & $1.10(0.97$ to 1.26$)$ & $<0.0001$ \\
\hline PR of service vs non-manual & $1.43(1.16$ to 1.78$)$ & $1.07(0.93$ to 1.24$)$ & $1.14(1.00$ to 1.30$)$ & $1.11(0.97$ to 1.28$)$ & 1.19 (1.02 to 1.39$)$ & $1.03(0.85$ to 1.25$)$ & $<0.0095$ \\
\hline
\end{tabular}


Among non-manual workers, the current smoking rates in general managers and professionals were higher than in office workers apart from in 2010 and 2011. Among manual workers, the current smoking rates in the elementary occupational group decreased dramatically from $2007(68.0 \%)$ to $2012(41.6 \%)$. The current smoking rate of service or sales workers was greatest in 2011 $(54.7 \%)$. Current smoking was more likely and prevalent in manual compared with non-manual workers in 2007 (OR 2.00, 95\% CI 1.43 to 2.80; PR $1.33,95 \%$ CI 1.12 to $1.59)$, but the difference between the groups reduced over time (in 2012: OR 1.41, 95\% CI 1.05 to 1.88; PR $1.10,95 \%$ CI 0.97 to 1.26$)$. The OR and PR for current smoking in sales workers compared with non-manual workers fluctuated over time from 2007 to 2012, but tended to decrease ( $\mathrm{p}$ for trend $<0.05$ ) (table 1 ).

Age-standardised rates of heavy smoking in South Korean men aged 25-64 years are shown (table 2). The rate of heavy smoking decreased from 2007 to 2012 (7.59\% in 2007 and $5.84 \%$ in 2012). Trends for heavy smoking rates to decrease were observed in manual, non-manual and service or sales workers ( $\mathrm{p}$ for trend $<0.0001)$. Among the three occupational groups, the prevalence of heavy smoking from 2007 to 2012 was highest in manual workers. Among non-manual workers, heavy smoking was more prevalent among general managers and professionals than among office workers. Among manual workers, the heavy smoking prevalence rates in the elementary occupational group decreased dramatically from $8.30 \%$ (2007) to $2.99 \%$ (2012). The heavy smoking rates in service or sales workers fluctuated but decreased overall from $8.52 \%$ (2007) to $5.80 \%$ (2012). Unlike current smoking rates, the likelihood and prevalence of heavy smoking became greater in manual workers compared with non-manual workers over the period 2007 (OR 1.67, 95\% CI 0.88 to 3.18; PR $1.50,95 \%$ CI 0.86 to 2.63 ) to 2012 (OR $3.11,95 \%$ CI 1.63 to 5.93; PR 2.83, 95\% CI 1.62 to 4.96 ) ( $\mathrm{p}$ for trend $<0.0001)$. The likelihood and prevalence of heavy smoking in service or sales workers compared with nonmanual workers did not change significantly from 2007 (OR $1.62,95 \%$ CI 0.88 to 3.18 ; PR $1.46,95 \%$ CI 0.71 to 3.01 ) to 2012 (OR 2.04, 95\% CI 0.80 to 5.16; PR 2.39, $95 \%$ CI 1.15 to 4.96 ).

The results of logistic regression analyses for heavy smoking are reported in table 3. Moderate to severe stress, depressive mood, suicidal thoughts and long working hours $(\geq 60 \mathrm{~h} /$ week) were all significantly associated with heavy smoking. Education about smoking cessation within the previous year was not significantly associated with the outcome of heavy smoking. In multivariable analysis, moderate to severe stress, depressive mood and long working hours $(\geq 60 \mathrm{~h} /$ week) remained significant after adjusting for age and other variables including stress, depressive mood, suicidal thought, working hours and education for smoking cessation. Long working hours ( $\geq 60 \mathrm{~h} /$ week) had the greatest association with heavy smoking (OR 1.41, $95 \%$ CI 1.13 to 1.75$)$.

\section{DISCUSSION}

There are two main results in this study. First, heavy smoking rate in manual workers was higher than that in non-manual workers, and the difference between the groups increased over time in contrast to the current smoking rate. Second, stress, depressive mood and long working hours $(\geq 60 \mathrm{~h} /$ week) were associated with heavy smoking.

According to Jang et $a l^{17}$ the difference in current smoking rate between manual and non-manual workers increased from 1998 to 2005 and then decreased from 2005 to 2009 . Overall, these results indicate that the difference in the current smoking rate between manual and non-manual workers has been diminishing since 2005, although smoking remains more likely and more prevalent in manual workers.

The observed increase in current smoking rate in nonmanual and service or sales workers may be associated with the economic crisis of 2008. The economic crisis induced the restructuring and personnel reduction of many companies, especially financial institutions, which increased job insecurity, especially among non-manual and service workers, and may have led to increased rates of smoking in these groups. Manual workers were relatively unaffected by the restructuring, possibly explaining why their smoking rate did not show a response to the crisis.

The observation that differences in heavy smoking rates between manual and non-manual workers increased over time indicates that antismoking policies were less effective in manual workers who smoked heavily compared with non-manual workers. Stress, depressive mood and long working hours were all significantly associated with heavy smoking.

Current smoking rate is different by age group. Current smoking rate increased with age and was highest in the 30s age group, and then decreased with age. ${ }^{21} 22$ On the other hand, the rate of smoking cessation increased with age. In addition to age, various other factors have been reported to be associated with current smoking. So and $\mathrm{Yeo}^{23}$ reported that various factors including low educational level of an individual and parents were associated with early smoking initiation. Low education level was also reported to be related to the quantity of cigarettes smoked by smokers. ${ }^{24}$ Low socioeconomic status was reported to be related to a failure of smoking cessation. ${ }^{25}$ Stressful events in early life might be a risk factor for early smoking initiation in adolescence. ${ }^{26}$ Race, ethnicity and culture were reported to be factors related to current smoking prevalence. ${ }^{27}$

Jang et $a t^{28}$ reported that the most dominant motivation to smoke was reported to be habit, followed by stress. They also reported that risk for current smoking increased directly in proportion to increased psychological stress. Both occupational and non-occupational stress were reported to be related to smoking. ${ }^{29}$ In this study, stress was a significant variable related to heavy 
Table 2 Age-standardised prevalence rates $(95 \% \mathrm{Cl})$, OR and prevalence ratio (PR) of heavy smokers; data on Korean men aged 25-64 years participating in the Korean National Health and Nutrition Examination Survey

\begin{tabular}{|c|c|c|c|c|c|c|c|}
\hline & 2007 & 2008 & 2009 & 2010 & 2011 & 2012 & $\begin{array}{l}p \text { For } \\
\text { trend }\end{array}$ \\
\hline Total & 7.59 (6.52 to 8.66$)$ & 8.24 (7.88 to 8.69$)$ & $6.83(6.50$ to 7.17$)$ & 6.50 (6.08 to 6.92$)$ & 5.29 (4.86 to 5.72$)$ & 5.84 (5.30 to 6.38$)$ & $<0.0001$ \\
\hline Non-manual & 5.78 (3.81 to 7.35$)$ & 5.68 (4.73 to 6.63$)$ & $4.92(4.25$ to 5.59$)$ & 4.72 (3.62 to 5.83$)$ & 4.35 (3.50 to 5.20$)$ & 2.65 (2.05 to 3.24$)$ & $<0.0001$ \\
\hline $\begin{array}{l}\text { General managers and } \\
\text { professionals }\end{array}$ & 6.94 (3.43 to 10.5$)$ & 6.28 (4.73 to 7.82$)$ & 5.46 (4.19 to 6.73$)$ & 5.68 (3.80 to 7.56$)$ & 4.83 (3.21 to 6.46$)$ & 3.69 (2.33 to 5.06$)$ & - \\
\hline Office workers & 3.20 (1.93 to 4.47$)$ & 4.98 (1.97 to 7.99$)$ & 3.90 (2.71 to 5.10$)$ & 3.58 (0.92 to 6.24$)$ & 4.22 (1.88 to 6.56$)$ & 0.75 (0.54 to 0.96$)$ & - \\
\hline Manual & $10.2(6.38$ to 13.9$)$ & 10.3 (8.96 to 11.7$)$ & 9.44 (8.00 to 10.9$)$ & $8.70(6.57$ to 10.8$)$ & 7.17 (5.65 to 8.69$)$ & 7.89 (6.27 to 9.52$)$ & $<0.0001$ \\
\hline $\begin{array}{l}\text { Agricultural and fishery } \\
\text { workers }\end{array}$ & $8.24(0.00$ to 19.0$)$ & 12.3 (0.00 to 29.3$)$ & $9.12(0.00$ to 18.4$)$ & 5.77 (0.00 to 12.9$)$ & 11.7 (0.00 to 25.7$)$ & 6.08 (2.66 to 9.50$)$ & - \\
\hline $\begin{array}{l}\text { Craft and related workers, } \\
\text { plant and machine operators } \\
\text { and assemblers }\end{array}$ & 9.46 (4.38 to 14.5$)$ & 10.7 (8.61 to 12.8$)$ & 10.2 (7.91 to 12.5$)$ & $9.10(6.23$ to 12.0$)$ & 5.68 (4.27 to 7.09$)$ & $8.85(6.10$ to 11.6$)$ & - \\
\hline $\begin{array}{l}\text { Elementary occupations } \\
\text { (construction and mining) }\end{array}$ & $8.30(0.00$ to 22.3$)$ & 7.42 (3.60 to 11.2 ) & 4.99 (2.61 to 7.38$)$ & $7.47(0.00$ to 18.3$)$ & $4.87(0.00$ to 12.6$)$ & 2.99 (0.91 to 5.07$)$ & - \\
\hline Service or sales workers & 8.52 (3.39 to 13.7 ) & 6.31 (3.65 to 8.97 ) & 8.43 (5.35 to 11.5$)$ & 6.97 (3.15 to 10.8$)$ & $2.12(0.86$ to 3.38$)$ & $5.80(2.45$ to 9.15$)$ & $<0.0001$ \\
\hline OR of manual vs non-manual & 1.67 (0.88 to 3.18$)$ & $1.82(1.16$ to 2.84$)$ & 1.95 (1.23 to 3.05$)$ & 2.09 (1.18 to 3.70$)$ & 1.56 (0.89 to 2.73$)$ & 3.11 (1.63 to 5.93$)$ & $<0.0001$ \\
\hline OR of service vs non-manual & $1.62(0.72$ to 3.64$)$ & 1.14 (0.56 to 2.33$)$ & 1.76 (1.07 to 2.88$)$ & 1.68 (0.78 to 3.59$)$ & $0.47(0.14$ to 1.55$)$ & $2.04(0.80$ to 5.16$)$ & 0.4420 \\
\hline PR of manual vs non-manual & 1.50 (0.86 to 2.63$)$ & 1.71 (1.20 to 2.44$)$ & 1.69 (1.17 to -2.42$)$ & 1.93 (1.28 to 2.93$)$ & 1.41 (0.89 to 2.22$)$ & 2.83 (1.62 to 4.96$)$ & $<0.0001$ \\
\hline PR of service vs non-manual & $1.46(0.71$ to 3.01$)$ & 0.99 (0.58 to 1.70$)$ & 1.57 (0.99 to 2.49$)$ & $1.29(0.72$ to 2.31$)$ & $0.40(0.14$ to 1.13$)$ & 2.39 (1.15 to 4.96$)$ & 0.6212 \\
\hline
\end{tabular}


Table 3 Factors associated with heavy smoking

\begin{tabular}{|c|c|c|}
\hline & Model 1 & Model 2 \\
\hline Stress & 1.43 (1.18 to 1.72$)$ & 1.31 (1.01 to 1.61$)$ \\
\hline $\begin{array}{l}\text { Depressive } \\
\text { mood }\end{array}$ & $1.63(1.25$ to 2.11$)$ & $1.36(1.01$ to 1.83$)$ \\
\hline Suicidal thoughts & 1.49 (1.14 to 1.95$)$ & $1.29(0.95$ to 1.75$)$ \\
\hline $\begin{array}{l}\text { Long working } \\
\text { hours ( } \geq 60 \mathrm{~h} \text { per } \\
\text { week) }\end{array}$ & 1.46 (1.17 to 1.81$)$ & 1.41 (1.13 to 1.75$)$ \\
\hline $\begin{array}{l}\text { Education for } \\
\text { smoking } \\
\text { cessation* }\end{array}$ & $1.03(0.76$ to 1.38$)$ & 0.93 (0.69 to 1.26$)$ \\
\hline \multicolumn{3}{|c|}{$\begin{array}{l}\text { Values are OR }(95 \% \mathrm{Cl}) \text {. Model } 1 \text { was adjusted for age. Model } 2 \\
\text { was adjusted for age, stress, depressive mood, suicidal thoughts, } \\
\text { working hours and education on smoking cessation. } \\
\text { "Participants reported having experience of education on smoking } \\
\text { cessation within the previous year. }\end{array}$} \\
\hline
\end{tabular}

smoking. According to the results of previous studies and this study, stress is related to current smoking and heavy smoking.

Depression is significantly related to smoking: smokers with depression are less likely to quit smoking ${ }^{30} 31$ and are more likely to experience severe withdrawal symptoms compared with smokers who are not depressed. ${ }^{32}$ Malpass and Higgs $^{33}$ report that enhanced craving might play a role in the maintenance of smoking in depression. Depressive mood is also one of the significant factors associated with heavy smoking in this study.

Some studies reported an association between long working hours and current smoking prevalence. Jang et $a t^{28}$ reported that Korean workers who worked long hours had a higher current smoking prevalence than a reference group which did not work long hours. Artazcoz et al and Cho et $a l^{3435}$ reported that those who work long hours have a higher current smoking prevalence than those who do not. It is also reported that long working hours disturb work-life balance and emotional well-being. ${ }^{36}{ }^{37}$ Therefore, it is possible that job stress, work-life imbalance and disturbed emotional wellbeing are all associated with the higher current smoking prevalence in those who have long working hours.

This study has some limitations. First, the question about smoking status did not clearly define what is meant by 'current smoking.' Differences in interpretation may give rise to inaccuracies in smoking rate. For example, some workers who were trying to give up smoking may have been classed inaccurately as ex-smokers rather than as current smokers. This would lead to an underestimation of the current smoking prevalence rate. However, this was relatively unimportant in this study, which focused on heavy smoking. Heavy smoking was clearly defined, and therefore the prevalence is thought to be accurate. Second, this study considered factors associated with smoking, but only those related to working conditions. Information about many extrinsic factors (such as socioeconomic status, education and others), which could be related to current and heavy smoking, was not available. This highlights the need for future studies considering these factors.

In South Korea, the National Health Promotion Act was published in 1995. This law contains the antismoking policy, which includes the regulation of tobacco advertisement, designation for smoke-free buildings and zones, attachment of age-verification devices to tobacco vending machines, and the imposition of tobacco charges. The antismoking campaign began in 1998 and focused on antismoking education and publicity programmes. The antismoking policy and campaign played an important role in smoking cessation in South Korea: prevalence rates of smoking and heavy smoking have decreased. According to the results of this study, however, neither contributed to smoking cessation by heavy smokers, especially manual workers, since the difference in heavy smoking rate between non-manual and manual workers gradually increased. According to this study, factors such as long working hours, stress and depressive mood may be related to heavy smoking. We recommend that antismoking policies should focus on heavy smokers, and that workplace antismoking programmes should consider the effects of long working hours and stress, particularly in manual workers.

Contributors B-GK, D-DP and Y-JP wrote the first draft of the paper, and carried out statistical analyses. J-IL and J-PM contributed to the interpretation and statistical analyses. H-RK contributed to the study design and interpretation of the paper. T-WJ Jang contributed to the study design, interpretation and draft of the paper.

Funding This research received no specific grant from any funding agency in the public, commercial or not-for-profit sectors.

\section{Competing interests None declared.}

Ethics approval This study was approved by the Institutional Review Board of St. Mary's Hospital (approval ID: KC14RISI0255).

Provenance and peer review Not commissioned; externally peer reviewed.

Data sharing statement Additional data can be accessed via the Dryad data repository at http://datadryad.org/ with the doi:10.5061/dryad.3ng27.

Open Access This is an Open Access article distributed in accordance with the Creative Commons Attribution Non Commercial (CC BY-NC 4.0) license, which permits others to distribute, remix, adapt, build upon this work noncommercially, and license their derivative works on different terms, provided the original work is properly cited and the use is non-commercial. See: http:// creativecommons.org/licenses/by-nc/4.0/

\section{REFERENCES}

1. Weiderpass $E$, Labrèche $F$. Malignant tumors of the female reproductive system. Saf Health Work 2012;3:166-80.

2. Sasco AJ, Secretan MB, Straif K. Tobacco smoking and cancer: a brief review of recent epidemiological evidence. Lung Cancer 2004;45(Suppl 2):S3-9.

3. Jindal SK, Aggarwal AN, Gupta D. A review of population studies from India to estimate national burden of chronic obstructive pulmonary disease and its association with smoking. Indian J Chest Dis Allied Sci 2001;43:139-47.

4. Messner B, Bernhard D. Smoking and cardiovascular disease: mechanisms of endothelial dysfunction and early atherogenesis. Arterioscler Thromb Vasc Biol 2014;34:509-15. 
5. Jha P, Ramasundarahettige C, Landsman V, et al. 21st-century hazards of smoking and benefits of cessation in the United States. N Engl J Med 2013;368:341-50.

6. Park EJ, Koh HK, Kwon JW, et al. Secular trends in adult male smoking from 1992 to 2006 in South Korea: age-specific changes with evolving tobacco-control policies. Public Health 2009;123:657-64.

7. Erren TC, Jacobsen M, Piekarski C. Synergy between asbestos and smoking on lung cancer risks. Epidemiology 1999;10:405-11.

8. Kharchenko TV, Arzhavkina LG, Sinyachkin DA, et al. Smoking as an additional risk factor for the staff of chemically hazardous production facilities. Gig Sanit 2014:77-80. (in Russian).

9. Meenakshi C, Mohankumar MN. Synergistic effect of radon in blood cells of smokers - an in vitro study. Mutat Res 2013;757:79-82.

10. Attarchi M, Dehghan $\mathrm{F}$, Afrasyabi M, et al. Combined effect of cigarette smoking and occupational exposures on lung function: a cross-sectional study of rubber industry workers. Workplace Health Saf 2013;61:213-20.

11. Vineis P, Esteve J, Terracini B. Bladder cancer and smoking in males: types of cigarettes, age at start, effect of stopping and interaction with occupation. Int J Cancer 1984;34:165-70.

12. Tsugane $\mathrm{S}$, Watanabe $\mathrm{S}$, Sugimura $\mathrm{H}$, et al. Smoking, occupation and family history in lung cancer patients under fifty years of age. Jpn J Clin Oncol 1987;17:309-17.

13. Thompson B, Emmons K, Abrams D, et al. ETS exposure in the workplace. Perceptions and reactions by employees in 114 work sites. Working Well Research Group [corrected]. J Occup Environ Med 1995;37:1086-92.

14. Osinubi OY, Sinha S, Rovner E, et al. Efficacy of tobacco dependence treatment in the context of a "smoke-free grounds" worksite policy: a case study. Am J Ind Med 2004;46:180-7.

15. Lang T, Nicaud V, Slama K, et al. Smoking cessation at the workplace. Results of a randomised controlled intervention study. Worksite physicians from the AIREL group. J Epidemiol Community Health 2000;54:349-54.

16. Brownson RC, Hopkins DP, Wakefield MA. Effects of smoking restrictions in the workplace. Annu Rev Public Health 2002;23:333-48.

17. Jang TW, Kim HR, Choi SE, et al. Smoking rate trends in Korean occupational groups: analysis of KNHANES 1998-2009 data. J Occup Health 2012;54:452-8.

18. Liu ZY, He XZ, Chapman RS. Smoking and other risk factors for lung cancer in Xuanwei, China. Int J Epidemiol 1991;20:26-31.

19. Chen CC, Li TC, Chang PC, et al. Association among cigarette smoking, metabolic syndrome, and its individual components: the metabolic syndrome study in Taiwan. Metabolism 2008;57:544-8.

20. Korea Centers for Disease Control and Prevention. Korean National Health and Nutrition Examination Survey. 2012. http://knhanes.cdc.go.kr

21. Marston L, Carpenter JR, Walters KR, et al. Smoker, ex-smoker or non-smoker? The validity of routinely recorded smoking status in UK primary care: a cross-sectional study. BMJ Open 2014;4: e004958.

22. Siegel M. Measuring age-specific variations in income-related inequalities in smoking behavior in Germany. Health Psychol Behav Med 2014;2:412-23.

23. So ES, Yeo JY. Factors associated with early smoking initiation among Korean adolescents. Asian Nurs Res (Korean Soc Nurs Sci) 2015;9:115-19.

24. Giskes K, Kunst AE, Benach J, et al. Trends in smoking behaviour between 1985 and 2000 in nine European countries by education. $J$ Epidemiol Community Health 2005;59:395-401.

25. Hiscock R, Dobbie F, Bauld L. Smoking cessation and socioeconomic status: an update of existing evidence from a national evaluation of english stop smoking services. Biomed Res Int 2015;2015:274056.

26. lakunchykova OP, Andreeva TI, Nordstrom DL, et al. The impact of early life stress on risk of tobacco smoking initiation by adolescents. Addict Behav 2015;50:222-8.

27. Lawrence EM, Pampel FC, Mollborn S. Life course transitions and racial and ethnic differences in smoking prevalence. Adv Life Course Res 2014;22:27-40.

28. Jang SM, Ha EH, Park H, et al. Relationship between Work Hours and Smoking Behaviors in Korean Male Wage Workers. Ann Occup Environ Med 2013;25:35.

29. Hassani S, Yazdanparast T, Seyedmehdi SM, et al. Relationship of occupational and non-occupational stress with smoking in automotive industry workers. Tanaffos 2014;13:35-42.

30. Clancy N, Zwar N, Richmond R. Depression, smoking and smoking cessation: a qualitative study. Fam Pract 2013;30:587-92.

31. Niaura R, Britt DM, Shadel WG, et al. Symptoms of depression and survival experience among three samples of smokers trying to quit. Psychol Addict Behav 2001;15:13-7.

32. Niaura R, Britt DM, Borrelli B, et al. History and symptoms of depression among smokers during a self-initiated quit attempt. Nicotine Tob Res 1999;1:251-7.

33. Malpass D, Higgs S. Acute psychomotor, subjective and physiological responses to smoking in depressed outpatient smokers and matched controls. Psychopharmacology (Berl) 2007;190:363-72.

34. Cho YS, Kim HR, Myong JP, et al. Association between work conditions and smoking in South Korea. Saf Health Work 2013;4:197-200.

35. Artazcoz L, Cortès I, Borrell C, et al. Gender perspective in the analysis of the relationship between long workhours, health and health-related behavior. Scand J Work Environ Health 2007;33:344-50.

36. Lee DJ, Fleming LE, Arheart KL, et al. Smoking rate trends in US occupational groups: the 1987 to 2004 National Health Interview Survey. J Occup Environ Med 2007;49:75-81.

37. Davies N. The work-life balance. Nurs Stand 2014;29:63. 